\title{
Macular Hole Development After Vitrectomy for Floaters: A Case Report
}

\author{
Andrea Appeltans · Marco Mura · Giulio Bamonte (D)
}

Received: August 28, 2017 / Published online: October 11, 2017

(C) The Author(s) 2017. This article is an open access publication

\begin{abstract}
Introduction: The purpose of this report is to describe a case of macular hole development after vitrectomy for floaters with induction of posterior vitreous detachment.

Case Report: A 44-year-old otherwise healthy man presented with visually debilitating floaters in his right eye; these had been present for more than 2 years. Preoperative examination was unremarkable in both eyes, apart from some degree of vitreous degeneration in the right eye. Preoperative visual acuity was 20/20 bilaterally. A 25-gauge transconjunctival sutureless pars plana complete vitrectomy with induction of posterior vitreous detachment was performed in the right eye. Upon examination 1 month after surgery, a small full-thickness
\end{abstract}

Enhanced content To view enhanced content for this article go to http://www.medengine.com/Redeem/ 22CCF0602F9B491A.

\section{A. Appeltans · G. Bamonte ( $\square)$}

Department of Ophthalmology, Universitair

Ziekenhuis Brussel, Vrije Universiteit Brussel,

Brussels, Belgium

e-mail: giuliobamonte@hotmail.com

M. Mura

The Wilmer Eye Institute, Johns Hopkins University

School of Medicine, Baltimore, MD, USA

\section{Mura}

The King Khaled Eye Specialist Hospital, Riyadh, Kingdom of Saudi Arabia macular hole was detected in the right eye. Visual acuity was diminished to 20/80. The macular hole was closed after a second vitrectomy with internal limiting membrane peeling and gas tamponade.

Conclusion: Macular hole development should be listed as a possible complication of vitrectomy for visually debilitating floaters when a posterior vitreous detachment is induced during surgery.

Keywords: Macular hole; Vitrectomy; Vitreous floaters

\section{INTRODUCTION}

Since the introduction of transconjunctival vitrectomy systems, vitrectomy for visually debilitating floaters has gained increasingly greater acceptance among surgeons [1]. Functional and anatomical results are excellent; however, a range of complications have been reported including cataract, iatrogenic retinal tears, retinal detachment, choroidal hemorrhage, and proliferative vitreoretinopathy $[1,2]$.

Macular hole development has been described after vitrectomy for diabetic macular edema, optic pit maculopathy, vein occlusion, and vitreoretinal interface disorders $[3,4]$. More recently, up to $5 \%$ incidence of macular hole occurrence has been reported after intravitreal injection of Ocriplasmin (Jetrea, 
Thrombogenics) for the treatment of vitreomacular traction, as a consequence of the enzymatic induction of vitreomacular separation [5].

We describe here the case of a relatively young patient undergoing vitrectomy for floaters with induction of a posterior vitreous detachment (PVD), who developed a full-thickness macular hole postoperatively.

\section{CASE REPORT}

A 44-year-old otherwise healthy man presented to our department complaining of disturbing floaters in his right eye for more than 2 years. On examination, best corrected visual acuity (BCVA) was 20/20 in both eyes (OU) with myopic correction bilaterally of -1 diopter. Anterior segment and fundus examination were unremarkable apart from some degree of vitreous degeneration more pronounced in the right than in the left. No PVD was detected in OU. After detailed explanation of the possible risks and benefits of vitrectomy a 6-month period of observation was advised, after which surgery was carried out because of persistence of symptoms. A 25-gauge transconjunctival sutureless pars plana vitrectomy (surgeon G.B.) was performed using the Alcon Constellation system (Alcon Laboratories Inc., Fort Worth, TX). After core vitrectomy, PVD was induced with aspiration from the cutter after injection of a small amount of triamcinolone acetonide to visualize the vitreous cortex. Careful peripheral vitrectomy with vitreous base shaving was achieved with scleral indentation. The vitreous cavity was filled with balanced salt solution at the end of the procedure.

Upon examination 1 month after surgery, a small full-thickness macular hole was detected in the right eye along with wrinkling of the retinal surface. BCVA was diminished to 20/80 (Fig. 1). As a result of persistence of the macular hole, a second vitrectomy was performed 3 weeks later, with peeling of both an epiretinal membrane (ERM) and the internal limiting membrane. The vitreous cavity was filled with a mixture of air and 20\% sulfur hexafluoride. Postoperatively, the patient was asked to maintain a reading position for $6 \mathrm{~h}$ per day for 3 days and not to sleep on his back for a week. One month afterwards, after complete disappearance of the air/gas mixture bubble, the macular hole was closed with partial restoration of BCVA up to 20/25. Consent for the publication for this case report and any additional related information was taken from the patient involved in the study.

\section{DISCUSSION}

Primary floaters stem from normal aging processes of the vitreous body and are common after the occurrence of PVD, as a result of the dense collagen matrix of the vitreous cortex [1]. Treatment is usually unnecessary, and mostly limited to watchful observation and reassurance, as disturbances rapidly subside in the vast majority of people. A subset of patients, however, complains of persistent symptoms with significant impact on the quality of life, for whom interventional options, such as Nd:YAG laser and vitrectomy, are increasingly being considered [1].

Recent studies have shown that disturbing floaters may also be more prevalent than previously thought in young patients without a PVD, with a negative impact on the quality of life that is greater than previously appreciated $[1,6]$. While it is usually recommended to postpone surgical options as long as possible in this subset of patients, vitrectomy may be the only option to eradicate the problem for those suffering from persistent debilitating vitreous opacities.

When performing vitrectomy for floaters in the absence of a pre-existent PVD, surgeons usually have two possibilities: either a complete vitrectomy with induction of a PVD or minimal removal of the central vitreous in front of the macula $[7,8]$.

A minimally invasive approach limited to the removal of the central gel enables a much easier and faster surgery compared to a more complete vitrectomy with induction of PVD. In addition, preservation of $3-4 \mathrm{~mm}$ of retrolental vitreous may limit postoperative cataract development, which may be of particular 


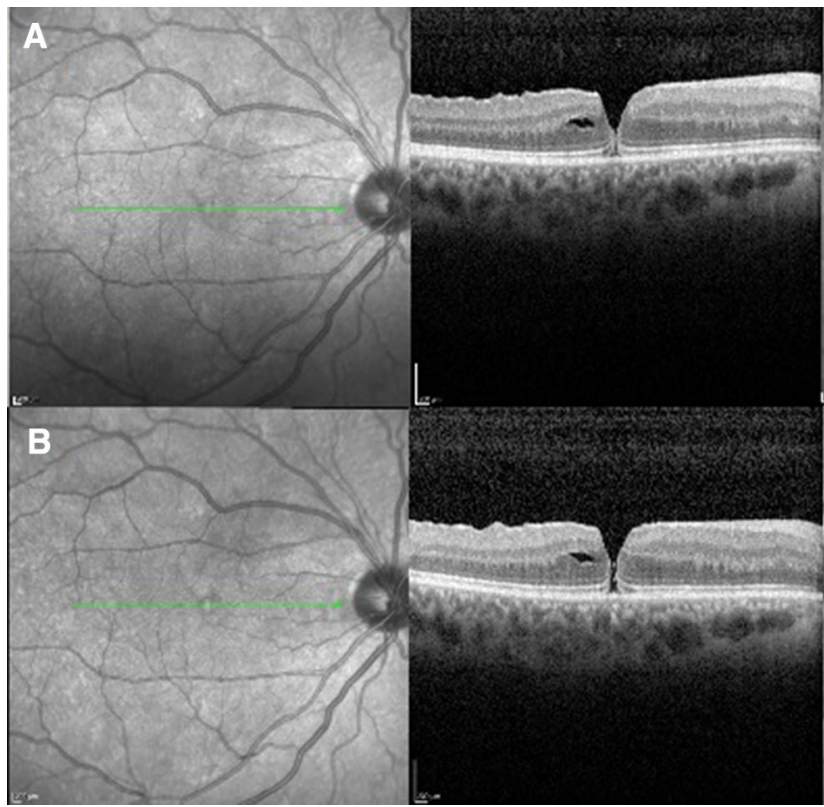

Fig. 1 Spectral domain optical coherence tomography (SD-OCT) images. a A small macular hole had developed 1 month after vitrectomy for floaters. Wrinkling of the retinal surface due to an epiretinal membrane was also

advantage in young patients who are still able to accommodate $[1,7]$. Finally, by not inducing a PVD the occurrence of iatrogenic peripheral breaks may also be limited. Sebag et al., for instance, reported less than 1\% incidence of iatrogenic retinal breaks with minimally invasive vitrectomy, while Tan et al. reported an incidence of $16.4 \%$ with PVD induction and complete vitrectomy $[7,8]$.

On the other hand, leaving the posterior cortex adherent to the retina at the end of surgery may lead to postoperative vitreous detachment and therefore to a higher occurrence of late onset retinal breaks and more importantly retinal detachments as in the studies by Schulz-Key et al. and de Nie et al. $[9,10]$. For this reason, even in young patients undergoing vitrectomy for floaters, our preference is always to induce a PVD and perform vitreous removal as thoroughly as possible as we believe this approach to be the safest in the long term.

However, we describe here the case of a patient undergoing surgery for vitreous floaters removal with induction of a PVD, who

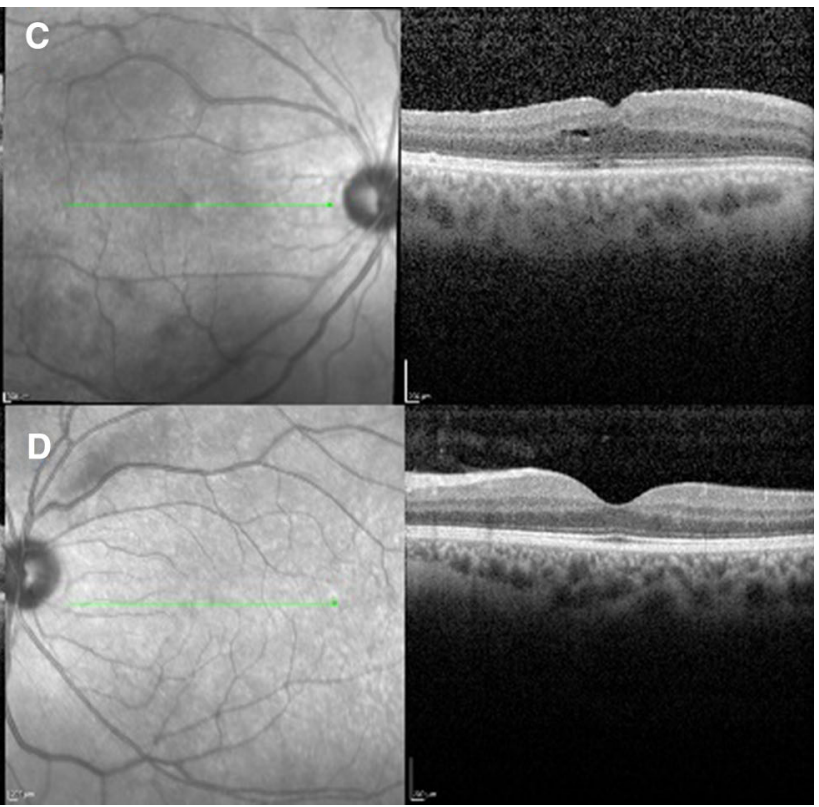

visible. b At 7 weeks after surgery the macular hole was slightly enlarged. c The macular hole was closed after subsequent surgery. $\mathbf{d}$ Left eye, normal macula

developed a full-thickness macular hole 1 month after vitrectomy. This short-term complication, to the best of our knowledge, has not been previously reported after vitrectomy for floaters.

Idiopathic macular holes are full-thickness retinal defects in the foveal neurosensory retina.

The pathogenesis of macular hole formation is widely accepted as an abnormal anteroposterior and tangential vitreous traction performed in the foveal retinal surface [11].

Postvitrectomy macular hole development has been previously described, and it has been proposed that surgical detachment of the posterior hyaloid membrane creates anteroposterior traction on the fovea, and, during detachment, retinal layer damage occurs in the macular area and a full-thickness macular hole may develop [3, 4]. This mechanism may explain the development of a macular hole in our patient.

In addition, we observed in our case the presence of a thick ERM at the posterior pole, which may also have occurred as a consequence of the PVD induction during primary surgery 
and which also may have contributed to the onset of the macular hole.

Since we did not obtain a spectral domain optical coherence tomography (SD-OCT) of the macula preoperatively, it might also be that the macular hole or the ERM was present already before the operation; however, this is unlikely since preoperative BCVA in the right eye was normal and the patient did not complain of metamorphopsia. SD-OCT scan of the fellow naïve eye did not show any alteration.

Three weeks after primary surgery, the patient was operated on again with subsequent successful closure of the macular hole with partial recovery of visual acuity.

\section{CONCLUSION}

The possibility of macular hole development should be included in the list of complications when discussing risks and benefits of vitrectomy for floaters. As a preventive measure, SD-OCT of the macula should probably be routinely performed in every case undergoing vitrectomy for floaters whether or not in the setting of preoperative PVD, since the absence of symptoms cannot completely rule out the presence of any interface disorder. Fovea-sparing ERMs of very little lamellar macular holes are sometimes completely asymptomatic, but may worsen after vitrectomy.

\section{ACKNOWLEDGEMENTS}

No funding or sponsorship was received for this study or publication of this article. The article processing charges were funded by the authors. All named authors meet the International Committee of Medical Journal Editors (ICMJE) criteria for authorship for this manuscript, take responsibility for the integrity of the work as a whole, and have given final approval for the version to be published.

Disclosures. Giulio Bamonte and Andrea Appletans have nothing to disclose. Marco Mura is a consultant for Alcon.
Compliance with Ethics Guidelines. Consent for the publication for this case report and any additional related information was taken from the patient involved in the study.

Data Availability. All data generated or analyzed during this study are included in this published article.

Open Access. This article is distributed under the terms of the Creative Commons Attribution-NonCommercial 4.0 International License (http://creativecommons.org/licenses/ by-nc/4.0/), which permits any noncommercial use, distribution, and reproduction in any medium, provided you give appropriate credit to the original author(s) and the source, provide a link to the Creative Commons license, and indicate if changes were made.

\section{REFERENCES}

1. Milston R, Madigan MC, Sebag J. Vitreous floaters: etiology, diagnostics, and management. Surv Ophthalmol. 2016;61(2):211-27.

2. Wilkinson CP. Safety of vitrectomy for floatershow safe is safe? Am J Ophthalmol. 2011;151(6):919-20.

3. Lee SH, Park KH, Kim JH, et al. Secondary macular hole formation after vitrectomy. Retina. 2010;30(7):1072-7.

4. Shukla D, Rajendran A, Kim R. Macular hole formation and spontaneous closure after vitrectomy for central retinal vein occlusion. Graefes Arch Clin Exp Ophthalmol. 2006;244(10):1350-2.

5. Chatziralli I, Theodossiadis G, Xanthopoulou P, Miligkos M, Sivaprasad S, Theodossiadis P. Ocriplasmin use for vitreomacular traction and macular hole: a meta-analysis and comprehensive review on predictive factors for vitreous release and potential complications. Graefes Arch Clin Exp Ophthalmol. 2016;254(7):1247-56.

6. Webb BF, Webb JR, Schroeder MC, North CS. Prevalence of vitreous floaters in a community sample of smartphone users. Int J Ophthalmol. 2013;6(3):402-5.

7. Sebag J, Yee KM, Wa CA, Huang LC, Sadun AA. Vitrectomy for floaters: prospective efficacy 
analyses and retrospective safety profile. Retina. 2014;34(6):1062-8.

8. Tan HS, Mura M, Lesnik Oberstein SY, Bijl HM. Safety of vitrectomy for floaters. Am J Ophthalmol. 2011;151(6):995-8.

9. Schulz-Key S, Carlsson JO, Crafoord S. Longterm follow-up of pars plana vitrectomy for vitreous floaters: complications, outcomes and patient satisfaction. Acta Ophthalmol. 2011;89(2):159-65.
10. de Nie KF, Crama N, Tilanus MA, Klevering BJ, Boon CJ. Pars plana vitrectomy for disturbing primary vitreous floaters: clinical outcome and patient satisfaction. Graefes Arch Clin Exp Ophthalmol. 2013;251(5):1373-82.

11. Smiddy WE, Flynn HW Jr. Pathogenesis of macular holes and therapeutic implications. Am J Ophthalmol. 2004;137(3):525-37. 